\title{
Virtual Environments, Online Racial Discrimination, and Adjustment among a Diverse, School-Based Sample of Adolescents
}

\section{Citation}

Tynes, Brendesha M., Chad A. Rose, Sophia Hiss, Adriana J. Umaña-Taylor, Kimberly Mitchell, and David Williams. 2014. "Virtual Environments, Online Racial Discrimination, and Adjustment Among a Diverse, School-Based Sample of Adolescents." International Journal of Gaming and Computer-Mediated Simulations 6 (3) (July): 1-16. doi:10.4018/ijgcms.2014070101.

\section{Published Version}

doi:10.4018/ijgcms.2014070101

\section{Permanent link}

http://nrs.harvard.edu/urn-3:HUL.InstRepos:37231605

\section{Terms of Use}

This article was downloaded from Harvard University's DASH repository, and is made available under the terms and conditions applicable to Other Posted Material, as set forth at http:// nrs.harvard.edu/urn-3:HUL.InstRepos:dash.current.terms-of-use\#LAA

\section{Share Your Story}

The Harvard community has made this article openly available.

Please share how this access benefits you. Submit a story.

Accessibility 


\title{
Virtual Environments, Online Racial Discrimination, and Adjustment among a Diverse, School-Based Sample of Adolescents
}

Brendesha M. Tynes, University of Southern California, Los Angeles, CA, USA

Chad A. Rose, University of Missouri, Columbia, MO, USA

Sophia Hiss, University of Southern California, Los Angeles, CA, USA

Adriana J. Umaña-Taylor, Arizona State University, Tempe, AZ, USA

Kimberly Mitchell, University of New Hampshire, Durham, NH, USA

David Williams, Harvard University, Cambridge, MA, USA

\begin{abstract}
Given the recent rise in online hate activity and the increased amount of time adolescents spend with media, more research is needed on their experiences with racial discrimination in virtual environments. This cross-sectional study examines the association between amount of time spent online, traditional and online racial discrimination and adolescent adjustment, including depressive symptoms, anxiety and externalizing behaviors. The study also explores the role that social identities, including race and gender, play in these associations. Online surveys were administered to 627 sixth through twelfth graders in $K-8$, middle and high schools. Multiple regression results revealed that discrimination online was associated with all three outcome variables. Additionally, a significant interaction between online discrimination by time online was found for externalizing behaviors indicating that increased time online and higher levels of online discrimination are associated with more problem behavior. This study highlights the need for clinicians, educational professionals and researchers to attend to race-related experiences online as well as in traditional environments.
\end{abstract}

Keywords: $\quad$ Aggressive Behavior/Bullying, Anxiety, Depression, Discrimination, Internet, Technology

DOI: $10.4018 /$ ijgcms.2014070101

Copyright $($ C 2014, IGI Global. Copying or distributing in print or electronic forms without written permission of IGI Global is prohibited. 


\section{INTRODUCTION}

Racial discrimination is a common stressor and a growing threat to adolescent health and wellbeing. More specifically, within their lifetime, up to $94 \%$ of African American, Latino, and Asian youth have experienced traditional or face-to-face discrimination that was associated with their racial and ethnic background (Benner \& Kim, 2009; Dotterer, McHale, \& Crouter, 2009; Flanagan, Syvertsen, Gill, Gallay, \& Cumsille, 2009; Harris-Britt, Valrie, Kurtz-Costes, \& Rowley, 2007; Huynh \& Fuligni, 2010; Martin et al., 2011; Medvedeva, 2010; Neblett et al., 2008; Pachter, Szalacha, Bernstein, \& Coll, 2010). Much of the research in the area of traditional racial discrimination focuses on the perceived frequency of these experiences within the classroom, including unfair treatment due to race (Chavous, Rivas-Drake, Smalls, Griffin, $\&$ Cogburn, 2008), where respondents may be treated with less respect or harassed because of their race or ethnicity (Rivas-Drake, Hughes, \& Way, 2009; Shin, D’Antonio, Son, Kim, \& Park, 2011). To extend this body of research, some scholars have explored disparities and experiences of tracking, unfair discipline, perceptions of lower levels of intelligence, or receiving less academic praise and reinforcement than their white counterparts (Benner \& Kim, 2009; Dotterer et al., 2009; Cogburn, Chavous, \& Griffin, 2011).

\section{Race in Virtual Environments}

While the foundation of literature for traditional discrimination is grounded in decades of empirical investigation, little is known about adolescents' racial discrimination experiences in virtual environments. We define online racial discrimination as denigrating or excluding individuals or groups on the basis of race through the use of symbols, voice, video, images, text, and graphic representations. These experiences may resemble traditional discrimination and include being disrespected or being called race-related names (Gaylord-Harden \& Cunningham, 2009; Roberts, Gibbons, Ger- rard, Weng, Murry, Simons, \& Lorenz, 2012; Umaña-Taylor, Wong, Gonzales, \& Dumka, 2012). Online forms of racial discrimination occur in social networking sites, chat rooms, discussion boards, through text messaging, web pages, online videos, music, and online games. For example, a black female student from the prestigious Stuyvesant High School in New York was sent a video on Facebook in which white fellow students performed a five minute and forty second rap calling her "ni**er" and "ignorant," and threatening her with sexual violence. Images and text also construct racial minorities as inferior, unintelligent, as criminals and, in many cases, animals. They also mock African American skin color and body types, cultural practices, and history (Tynes, UmañaTaylor, Rose, Lin, \& Anderson, 2012).

In the mid-1990s, the Internet was lauded for its potential to usher in a color-blind society. As the medium proliferated, scholars argued it could eliminate racial cues from communication and lead to a more egalitarian electronic global village, where there would be no race, gender or infirmities (Ess, 2001; Negroponte, 1995). Though visual signifiers of race may have been removed in early virtual environments, research on adults shows that across a range of online communication settings (in internet relay chat, for example; Glaser et al., 2002; Kang, 2000; Nakamura, 2002; Kendall, 1998), race takes on a linguistic form. Once made visible through text, it has been found to be central to the culture of computer-mediated environments. Further, many of the social norms and ills that exist offline are often reproduced in adult online communities (Burkhalter, 1999). This is increasingly evident as images, videos, and graphic representations of the body become more prevalent online.

To address the question of whether similar findings to those found with adults would be found with adolescent populations, Tynes and colleagues (2004) conducted one of the earliest studies of race-related discourse in monitored versus unmonitored teen chat. They found that 37 out of 38 half-hour transcripts had at least one racial or ethnic utterance and that, in the 
14 more pages are available in the full version of this document, which may be purchased using the "Add to Cart" button on the product's webpage:

www.igi-global.com/article/virtual-environments-online-racial-

discrimination-and-adjustment-among-a-diverse-schoolbased-sample-of-adolescents/123194?camid=4v1

This title is available in InfoSci-Journals, InfoSci-Journal Disciplines Communications and Social Science. Recommend this product to your librarian: www.igi-global.com/e-resources/libraryrecommendation/?id=2

\section{Related Content}

Designing Games-Based Embedded Authentic Learning Experiences Penny de Byl (2009). Handbook of Research on Effective Electronic Gaming in Education (pp. 1068-1087).

www.igi-global.com/chapter/designing-games-based-embedded-

authentic/20137?camid=4v1a

Visual Analyses of the Creation of Avatars

Erik W. Black, Richard E. Ferdig, Joseph C. DiPietro, Feng Liu and Baird Whalen (2009). International Journal of Gaming and Computer-Mediated Simulations (pp. 90107).

www.igi-global.com/article/visual-analyses-creationavatars/2163?camid $=4 \mathrm{v} 1 \mathrm{a}$

Rhetorics, Simulations and Games: The Ludic and Satirical Discourse of Molleindustria

Gabriele Ferri (2013). International Journal of Gaming and Computer-Mediated Simulations (pp. 32-49).

www.igi-global.com/article/rhetorics-simulations-andgames/79930?camid=4v1a 
Problematizing Epistemology in Computer Games Research

Adam Mechtley (2015). International Journal of Gaming and Computer-Mediated

Simulations (pp. 68-81).

www.igi-global.com/article/problematizing-epistemology-in-computer-games-

research/133620?camid $=4 \mathrm{v} 1 \mathrm{a}$ 